\title{
AGING AS A FACTOR IN THE RENAL HEMODYNAMIC CHANGES INDUCED BY A STANDARDIZED PYROGEN
}

\author{
By ROGER K. MCDONALD, DAVID H. SOLOMON,1 AND \\ NATHAN W. SHOCK \\ (From the National Heart Institute, National Institutes of Health, Bethesda, Md., and the \\ Section on Gerontology, Baltimore City Hospitals, Baltimore, Md.)
}

(Submitted for publication September 25, 1950; accepted, March 6, 1951)

The functional and anatomic changes of the kidney associated with increasing age have been demonstrated convincingly. The evaluation of renal function in aged persons has demonstrated a progressive decrease in the urea clearance (1), glomerular filtration rate, effective renal plasma flow, and renal tubular transfer maxima $(2,3)$. These decreases in function fit well with the anatomic studies which hold that the degree of renal arteriosclerosis present in the aging population is sufficient to account for the decrease in renal parenchyma on a basis of restricted blood supply (4-7).

The anatomic studies also agree that the predominant picture of arterial degeneration is that of intimal thickening (lumen attenuation and occlusion) in the larger arteries (interlobar and interlobular) with progressively less sclerosis in the vessels as the observations extend toward the glomerulus. Even in the age group beyond 80 years, Bell notes that only about 20 per cent of the renal arterioles are involved in the sclerotic process, and this involvement is not severe (7). In his study of the relationship of age to renal atrophy in non-hypertensive individuals free from renal disease, Bell states, "Areas of atrophy are wedgeshaped and are caused by intimal atherosclerosis with occlusion of fairly large branches of the renal artery."

The present study is concerned with an evaluation of the functional status of the renal arterioles in an aging population free of hypertension and demonstrable renal disease. Since it is believed that the increase in renal blood flow following the intravenous administration of a pyrogen is in large part mediated through a decrease in renal arteriolar tonus (8), we have employed a standard-

\footnotetext{
1 Present address: Department of Medicine, Peter Bent Brigham Hospital, Boston, Mass.
}

ized pyrogen test to assay the capacity of the renal arterioles to dilate.

\section{METHODS}

Subjects. The 54 male subjects studied were divided into three age groups: young ( $Y$ ), age range $20-49$, mean age 36.6 years, $N=20$; middle $(M)$, age range $50-69$, mean age $58.8, \mathrm{~N}=20$; and old $(\mathrm{O})$, age range $70-84$, mean age 76.9 years, $\mathrm{N}=14$. The broad 30 -year age span of the young group was so selected because the downward age trend in renal function is not significant until after the age of 50 (2). That this fiinding applied well to the present group is indicated by the similarity of the mean resting effective renal plasma flows for two subgroups : age $20-34,609 \mathrm{cc} / \mathrm{min} . / 1.73 \mathrm{~m}^{2}$; age $35-49$, $599 \mathrm{cc} . / \mathrm{min} . / 1.73 \mathrm{~m}$. $^{2}$

The subjects were patients on the acute and chronic wards and residents of the Infirmary (Home for the Aged) of the Baltimore City Hospitals. All patients studied were ambulatory.

Except as noted, subjects were selected who met the following criteria: a) absence of history of physical evidence of renal disease, hypertension, or congestive heart failure, b) urinalyses (two or more) negative for protein by the heat and acetic acid coagulation test and for significant microscopic abnormalities, c) blood hemoglobin greater than 12 grams per cent, $d$ ) absence of electrocardiographic evidence of arrhythmia or A-V conduction defect, $e$ ) blood urea nitrogen within the limits for the different age groups as reported by Lewis and A1ving (1), and $f$ ) basal diastolic blood pressure below 90 $\mathrm{mm}$. Hg. No limits were placed on the systolic blood pressure, which ranged from 100 to $181 \mathrm{~mm}$. $\mathrm{Hg}$. In the old group, three of the subjects, though normotensive at the time of testing, showed cardiac enlargement and previous hypertensive blood pressure readings. Also in the old group an additional two subjects showed signs of congestive failure. However, the mean baseline renal function values and the mean renal hemodynamic response for these individuals were the same as the mean for the other nine subjects in this group.

Additional clinical examinations were made which were not used for exclusion of subjects. Heart size was estimated by $\mathrm{x}$-ray; seven subjects were included who showed cardiac enlargement (cardiac transverse diameter 10-20 per cent in six cases and 32 per cent in one case above normal for their height and weight). Electrocardiographic abnormalities suggestive of myocardial disease 
were noted in 11 subjects, eight of whom were in the old group. Palpable thickening and diminished pulsation of the brachial, radial, dorsal pedal, and posterior tibial arteries were noted. Retinal arteriosclerosis was graded by an ophthalmologist.

Test procedure. Subjects were studied in the postabsorptive state beginning at 8 a.m. Aminopyrine (0.6 gram) was given by mouth at four-hour intervals from 4 p.m. on the day preceding the test until 8 p.m. on the day of the test. Using the renal clearance technique of Goldring and Chasis (9) eleven 20-minute urine collection periods were carried out starting immediately after the intravenous administration of 50,000,000 killed typhoid organisms ( $0.05 \mathrm{cc}$. TAB vaccine). Blood samples were obtained through an indwelling femoral artery needle.

The sphygmomanometric blood pressure and the pulse rate by one-minute radial artery counts were determined at the fifth and 15th minute of each period. The average of the two determinations was recorded as the value for the period. Oral temperature was determined hourly during and for six to eight hours after the test.

Chemical methods. Inulin was determined in blood and urine by the method of Harrison (10). PAH was determined in blood and urine by the method of Bratton and Marshall (11) as modified by Smith and associates (12). Blood urea nitrogen was analyzed by the method of Van Slyke (13). Total serum proteins were determined by the micro-Kjeldahl method (14) on 12 of $20 \mathrm{Y}$ group subjects, 15 of $20 \mathrm{M}$ group subjects, and 11 of $14 \mathrm{O}$ group subjects. Hematocrits were determined by the Wintrobe method on the control blood samples drawn from each subject.

Analysis of data. Clearances of inulin and PAH were corrected to $1.73 \mathrm{~m}^{2}$ of body surface. Renal afferent and efferent hydraulic resistances were calculated according to the formulae of Lamport (15) and were expressed as $10^{8} \mathrm{~mm}$. $\mathrm{Hg}$ (min./cc.) (body surface $\mathrm{m}^{2} / 1.73 \mathrm{~m}^{2}$ ).

Mean blood pressure was taken as equal to the diastolic pressure plus one-half the pulse pressure. The mean serum protein values for the appropriate age group were used for the calculation of resistances in a few subjects where individual serum protein values were not available and an albumin globulin ratio of 2.2 was assumed for all subjects.

For each hemodynamic measure mean curves of the pyrogen reaction were constructed for each of the three age groups. In addition, to evaluate the significance of differences between age groups, individual response indices were computed as the difference between the baseline (average of the first two periods) and the peak response (average of the two consecutive periods which gave a maximum or minimum for the particular measurement). For the analysis of blood pressure responses, the average of periods $\mathrm{X}$ and $\mathrm{XI}$ was used instead of the individual maximum responses, because of qualitative differences in the blood pressure responses of the three age groups. The mean differences between age groups in the baseline values and response indices were evaluated for significance by the $t$ test. Only $t$ scores at the 1 per cent level of probability are reported as significant.
The rate of increase in $\mathrm{C}_{\mathrm{PAB}}$ was estimated as the slope of a straight line drawn by inspection through the points which included the period of rising $\mathrm{C}_{\mathbf{P A H}}$. The value for the individual was based on the average of slopes determined independently by two of the authors. The correlation between the two determinations was +0.98 .

\section{RESULTS}

Glomerular filtration rate $\left(\mathrm{C}_{\mathrm{IN}}\right)$. The mean baseline values for the $C_{I N}$ in the $Y, M$, and $O$ groups were $110.4,88.9$, and $62.4 \mathrm{cc} . / \mathrm{min}$., respectively (Table I). The course of the mean $\mathrm{C}_{\mathrm{IN}}$ was similar through the reaction in all three age groups in that there was neither a significant increase nor decrease present (Figure 1). Subjects occasionally showed a rise or fall in $C_{\text {IN }}$ which bore no relationship to the degree of their increase in $\mathrm{C}_{\mathrm{PAB}}$.

Effective renal plasma flow $\left(\mathrm{C}_{\mathrm{PAH}}\right)$. The mean baseline values for the $\mathrm{Y}, \mathrm{M}$, and $\mathrm{O}$ groups were 603,449 , and $277 \mathrm{cc} . / \mathrm{min}$., respectively (Table I). Baseline $\mathrm{C}_{\mathbf{P A B}}$ was unrelated to the presence or absence of any of the observed clinical characteristics. Thus, the mean baseline $\mathrm{C}_{\mathbf{P A B}}$ for subjects with retinal arteriosclerosis was not significantly different from the mean for those in the same age group with no retinal arteriosclerosis. The same was true for subjects with and without peripheral arteriosclerosis, elevation of systolic blood pressure, electrocardiographic abnormalities, or any combination of the observed clinical characteristics.

The group response curves are shown in Figure 1 for the three age groups. In this figure the simultaneity of time of onset, and the rate of $\mathrm{C}_{\mathbf{P A H}}$ increase are shown. The mean absolute increases in the clearance of $\mathrm{PAH}$ for the $\mathrm{Y}, \mathrm{M}$, and $\mathrm{O}$ groups were 416,368 , and $240 \mathrm{cc} . / \mathrm{min}$., respectively. Expressed as per cent of baseline value, the rise in $C_{P A B}$ for the $Y, M$, and $O$ groups was 71,86 , and 91 per cent, respectively (Table I).

In a further attempt to characterize the increase in $\mathrm{C}_{\mathrm{PAH}}$ of the different age groups, a slope for the rate of reaction of each individual was obtained as an expression of rate of response per unit of time. The values obtained for the $Y, M$, and $O$ groups were $5.9,4.7$, and $3.4 \mathrm{cc}$./min., respectively (Table I). Expressed as per cent of the baseline value, the rise in $C_{P A B}$ was $1.02,1.10$, and 1.35 per cent for the $Y, M$, and $O$ groups, respectively. 
TABLE I

Age differences in the average hemodynamic responses to pyrogen

\begin{tabular}{|c|c|c|c|c|c|c|}
\hline \multirow[b]{2}{*}{ Measurement } & \multicolumn{3}{|c|}{ Age groups } & \multicolumn{3}{|c|}{ Significance of differences* } \\
\hline & $\underset{20-49}{\mathbf{Y}} \mathrm{yrs}$. & $\underset{50-69}{M}$ yrs. & ${ }_{70-85}^{\circ}$ yrs. & $\mathbf{Y}-\mathbf{M}$ & $\mathbf{M}-\mathbf{O}$ & $\mathrm{x}-\mathrm{O}$ \\
\hline 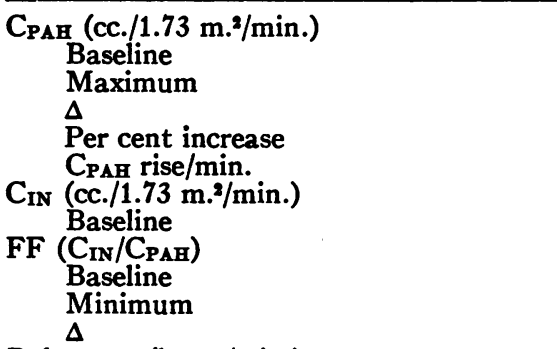 & $\begin{array}{c}603 \\
1019 \\
416 \\
71 \\
5.9 \\
110.4 \\
\\
.189 \\
.115 \\
.074\end{array}$ & $\begin{array}{c}449 \\
817 \\
368 \\
86 \\
4.7 \\
88.9 \\
\\
.206 \\
.123 \\
.083\end{array}$ & $\begin{array}{c}277 \\
517 \\
240 \\
91 \\
3.4 \\
62.4 \\
\\
.232 \\
.122 \\
.110\end{array}$ & $\begin{array}{r}\text { S } \\
\text { S } \\
\text { NS } \\
\text { NS } \\
\text { S } \\
\text { NS } \\
\text { NS } \\
\text { NS }\end{array}$ & $\begin{array}{r}\text { S } \\
\text { S } \\
\text { NS } \\
\text { PS } \\
\text { S } \\
\text { NS } \\
\text { NS } \\
\text { NS }\end{array}$ & $\begin{array}{r}\mathbf{S} \\
\mathbf{S} \\
\mathbf{S} \\
\mathbf{S} \\
\mathbf{S} \\
\mathbf{S} \\
\mathbf{N} \\
\mathbf{S}\end{array}$ \\
\hline $\begin{array}{l}\text { Pulse rate (beats/min.) } \\
\text { Baseline } \\
\text { Maximum } \\
\Delta \\
\text { Systolic blood pressure (mm. } \mathrm{Hg} \text { ) }\end{array}$ & $\begin{array}{l}67 \\
85 \\
18\end{array}$ & $\begin{array}{l}65 \\
80 \\
15\end{array}$ & $\begin{array}{l}60 \\
76 \\
16\end{array}$ & $\begin{array}{l}\text { NS } \\
\text { NS } \\
\text { NS }\end{array}$ & $\begin{array}{l}\text { PS } \\
\text { NS } \\
\text { NS }\end{array}$ & $\begin{array}{r}\text { SS } \\
\text { NS }\end{array}$ \\
\hline $\begin{array}{l}\text { Baseline } \\
\text { Periods X and XI }\end{array}$ & $\begin{array}{r}116 \\
114 \\
2\end{array}$ & $\begin{array}{r}124 \\
110 \\
14\end{array}$ & $\begin{array}{r}136 \\
121 \\
15\end{array}$ & $\begin{array}{l}\text { PS } \\
\text { NS } \\
\text { S }\end{array}$ & $\begin{array}{l}\text { NS } \\
\text { NS } \\
\text { NS }\end{array}$ & $\begin{array}{r}\mathbf{S} \\
\mathbf{N} \\
\mathbf{S}\end{array}$ \\
\hline $\begin{array}{l}\text { Diastolic blood pressure (mm. Hg) } \\
\text { Baseline } \\
\text { Periods X and XI } \\
\Delta \\
\text { Pulse pressure (mm. Hg) }\end{array}$ & $\begin{array}{l}77 \\
67 \\
10\end{array}$ & $\begin{array}{l}77 \\
63 \\
14\end{array}$ & $\begin{array}{l}75 \\
64 \\
11\end{array}$ & $\begin{array}{l}\text { NS } \\
\text { NS } \\
\text { NS }\end{array}$ & $\begin{array}{l}\text { NS } \\
\text { NS } \\
\text { NS }\end{array}$ & $\begin{array}{l}\text { NS } \\
\text { NS } \\
\text { NS }\end{array}$ \\
\hline $\begin{array}{l}\text { Baseline } \\
\text { Periods X and XI } \\
\Delta\end{array}$ & $\begin{array}{r}39 \\
47 \\
-8\end{array}$ & $\begin{array}{r}47 \\
47 \\
0\end{array}$ & $\begin{array}{r}61 \\
57 \\
4\end{array}$ & $\begin{array}{l}\text { PS } \\
\text { NS } \\
\text { S }\end{array}$ & $\begin{array}{l}\text { S } \\
\text { NS }\end{array}$ & $\begin{array}{r}\text { S } \\
\text { NS } \\
\text { S }\end{array}$ \\
\hline $\begin{array}{l}\mathrm{R}_{\mathrm{a}}\left(10^{3} \mathrm{~mm} . \mathrm{Hg}\right)(\min . / \mathrm{cc} .) \text { (body surface } \\
\left.\text { m.2/1.73 m. }{ }^{2}\right) \\
\text { Baseline } \\
\text { Minimum } \\
\Delta \\
\mathrm{R}_{\mathbf{0}}\left(10^{3} \mathrm{~mm} . \mathrm{Hg}\right)(\mathrm{min} . / \mathrm{cc} .) \text { (body surface }\end{array}$ & $\begin{array}{l}6.7 \\
3.6 \\
3.1\end{array}$ & $\begin{array}{r}15.5 \\
5.7 \\
9.8\end{array}$ & $\begin{array}{l}31.5 \\
13.6 \\
17.9\end{array}$ & $\begin{array}{l}\mathbf{S} \\
\mathbf{S} \\
\mathbf{S}\end{array}$ & $\begin{array}{l}\text { S } \\
\mathbf{S} \\
\mathbf{S}\end{array}$ & $\begin{array}{l}\mathbf{S} \\
\mathbf{S}\end{array}$ \\
\hline $\begin{array}{l}\text { m.2 }\left(1.73 \mathrm{~m} .{ }^{2}\right) \\
\text { Baseline } \\
\text { Minimum } \\
\Delta\end{array}$ & $\begin{array}{l}4.5 \\
2.0 \\
2.5\end{array}$ & $\begin{array}{l}8.2 \\
3.4 \\
4.8\end{array}$ & $\begin{array}{r}13.7 \\
5.2 \\
8.5\end{array}$ & $\begin{array}{l}\mathbf{S} \\
\mathbf{S} \\
\mathbf{S}\end{array}$ & $\begin{array}{l}\mathbf{S} \\
\mathbf{S} \\
\mathbf{S}\end{array}$ & $\begin{array}{l}\mathbf{S} \\
\mathbf{S} \\
\mathbf{S}\end{array}$ \\
\hline
\end{tabular}

* $\mathrm{S}=$ Significant $\quad$ PS = Probably Significant $(P<.01) \quad(P=.05$ to .01$)$

The differences in per cent increments for the three age groups were not statistically significant.

Thirteen subjects exhibited temperature rises of $1^{\circ}$ to $3^{\circ} \mathrm{F}$, and two subjects developed shaking chills of 20 minutes duration. In none of these subjects was there a significant departure of the hemodynamic response from that of the rest of the group.

Filtration fraction (FF). The mean baseline $\mathrm{FF}$ values for the $\mathrm{Y}, \mathrm{M}$, and $\mathrm{O}$ age groups were $0.189,0.206$, and 0.232 , respectively (Table I). The absolute fall in FF was greater in the $O$ group (0.110) than in the $M(0.083)$ and $Y$ groups $(0.074)$. At the height of the reaction the differences observed in the baseline values between age groups had disappeared (Figure 1 and Table I).
NS $=$ Not Significant

$(\mathrm{P}>.05)$

Pulse rate. The mean baseline pulse rates in the $Y, M$, and $O$ groups were 67,65 , and 60 , respectively (Table I). The time of onset and the absolute magnitude of pulse rate acceleration were the same for the three age groups (Figure 2 and Table I).

Blood pressures. The mean baseline systolic values for the $Y, M$, and $O$ groups were 116,124 , and $136 \mathrm{~mm}$. $\mathrm{Hg}$, respectively (Table $\mathrm{I}$ ). The $M$ and $O$ groups showed a fall in pressure while the $Y$ group remained constant throughout the reaction (Figure 2). In periods $\mathrm{X}$ and $\mathrm{XI}$ the residual differences between the age groups are not significant.

The mean baseline diastolic pressures were approximately the same $(75-77 \mathrm{~mm}$. $\mathrm{Hg})$ for the 




Fig. 1. Changes in $C_{\text {in }}, C_{\text {pah, and Ff during Pyrogen }}$ REACTION

Fifty million killed typhoid organisms were injected intravenously at 0 time.

O---- $-\mathrm{O}$ Mean value for 14 subjects in $\mathrm{O}$ group (70-85 yrs.)

$\triangle--\triangle$ Mean value for 20 subjects in $M$ group (50-69 yrs.)

Mean value for 20 subjects in $\mathrm{Y}$ group (20-49 yrs.)

different age groups. This is in part due to the setting of an upper limit of diastolic pressure by the criteria of subject selection. The average fall in diastolic pressure (Figure 2) was the same for all age groups.

A rise in pulse pressure occurred in the $\mathrm{Y}$ group (Figure 2 and Table I) as a result of an unchanged systolic pressure and a drop in diastolic pressure. The $\mathbf{M}$ group showed a commensurate fall in systolic and diastolic pressures with a resultant stable pulse pressure. The $O$ group manifested a fall in pulse pressure due to a greater fall in systolic than in diastolic pressure. There was no demonstrable relationship between the magnitude of pulse rate or pulse pressure change, or their product, and the magnitude of the $\mathrm{C}_{\mathbf{P A B}}$ response for the individuals in any age group.

Serum protein and hematocrit. Significant differences in serum protein values were observed among the three age groups. For serum protein the average values were $7.00,6.50$, and $6.10 \mathrm{~g} . / 100$ cc. for the $Y, M$, and $O$ groups, respectively. The average hematocrit values for the $M$ and $O$ groups were significantly lower than that for the $\mathrm{Y}$ group ( $\mathrm{Y}=0.44 ; \mathrm{M}=0.39 ; 0=0.39$ ).

Renal afferent resistance $\left(\mathrm{R}_{\mathrm{a}}\right)$. The mean baseline values for $R_{a}$ were $6.7,15.5$, and $31.510^{3}$ $\mathrm{mm}$. $\mathrm{Hg}$ (min./cc.) (body surface $\mathrm{m} .{ }^{2} / 1.73 \mathrm{~m}^{2}$ ), in the $\mathrm{Y}, \mathrm{M}$, and $\mathrm{O}$ groups, respectively (Table $\mathrm{I}$ ). The fall in $R_{a}$ occurred in all three groups (Figure 3 ) and was for the $O$ group 17.9, for the $M$ group 9.8, and for the Y group $3.110^{3} \mathrm{~mm}$. $\mathrm{Hg}$ (min./cc.) (body surface $\mathrm{m}^{2} / 1.73 \mathrm{~m}^{2}$ ). Because of the mathematical relationships of the formula used to calculate $R_{a}$, the fall in these values was determined largely by the changes in mean pressure.

Renal efferent resistance $\left(\mathrm{R}_{\mathrm{e}}\right)$. The mean baseline $R_{e}$ values were higher in the $O$ group than in the $\mathrm{M}$ and $\mathrm{Y}$ groups; the values were 13.7, 8.2, and $4.510^{3} \mathrm{~mm}$. $\mathrm{Hg}$ (min./cc.) (body surface $\mathrm{m}^{2}$ / $1.73 \mathrm{m.}^{2}$ ) respectively (Table $\mathrm{I}$ ). At the height of the pyrogen reaction, the divergence in values was

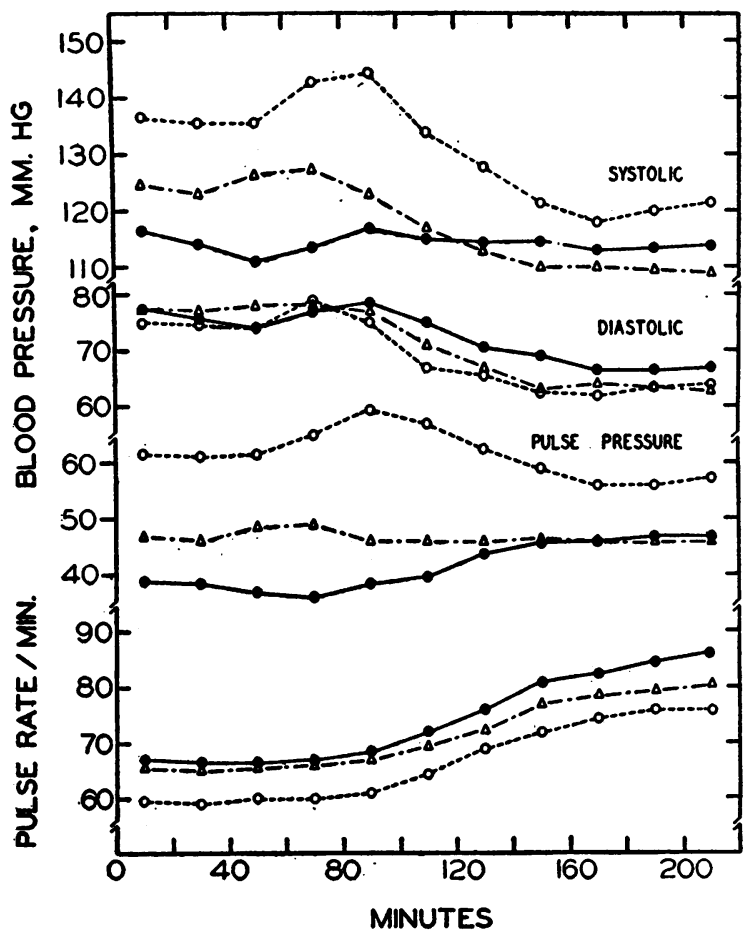

Fig. 2. Changes in Pulse Rate, Systolic, Diastolic, and Pulse Pressure during Pyrogen Reaction

Fifty million killed typhoid organisms were injected intravenously at 0 time.

- - - - $\bigcirc$ Mean value for 14 subjects in 0 group (70-85 yrs.)

$\triangle--\triangle$ Mean value for 20 subjects in $M$ group (50-69 yrs.)

Mean value for 20 subjects in $\mathrm{Y}$ group (20-49 yrs.) 




Fig. 3. Changes in Afferent and Efferent Renal Hydraulic Resistances during the Pyrogen ReACTION

Fifty million killed typhoid organisms were injected intravenously at 0 time.

O--- $-O$ Mean value for 14 subjects in 0 group (70-85 yrs.)

$\triangle---\triangle$ Mean value for 20 subjects in $M$ group (50-69 yrs.)

Mean value for 20 subjects in $Y$ group (20-49 yrs.)

less (Figure 3) ; although, the $R_{e}$ value for the $O$ group remained significantly higher than that of the $\mathrm{Y}$ and $\mathrm{M}$ groups.

\section{DISCUSSION}

The decrease in the baseline $\mathrm{C}_{\mathrm{IN}}$ and $\mathrm{C}_{\mathbf{P A B}}$ in the older age groups confirms results previously reported from this laboratory (2) and are consistent with the qualitative $(4,6,7)$, semi-quantitative (5), and quantitative (16) anatomic descriptions of the senile kidney. The progressively smaller absolute changes in renal plasma flow $\left(\mathrm{C}_{\mathrm{PAH}}\right)$ in the older subjects following pyrogen are also consistent with a progressive decrease in the renal parenchyma of the aged. On the other hand, the time of onset of the response, and the percentage increase in renal plasma flow were similar in the different age groups. Consequently, it must be concluded that the responsiveness to pyrogen of the vascular elements remaining in the aged kidney is not qualitatively different from that of the young kidney.
Since direct evidence of structural changes in the renal vessels could not be obtained, indirect evidence was sought in clinical estimates of the degree of retinal, peripheral, and central arteriosclerosis present in the subjects tested. It is of interest that no correlation was found between the estimates of the degree of arteriosclerosis in these regions and the decrement in renal function within a given age group.

The results of this study also confirm the previously reported increase in FF with age (2). Since there is no reduction in the tubular extraction of $\mathrm{PAH}$ in the aged kidney (17), a reasonable explanation of the increased FF found in the $\mathrm{O}$ group is an increase in the efferent arteriolar resistance. The decrease in $\mathrm{C}_{\mathrm{IN}}$ and $\mathrm{C}_{\mathrm{PAH}}$ with age may be explained on the basis of a decrease in the number of functioning nephrons, but the observed increase in FF cannot be accounted for simply on this basis. Some change in the renal vessels beyond the point of glomerular filtration equilibrium must be postulated to account for this phenomenon. Such alteration might be present in the efferent arterioles either as structural changes, such as sclerosis, or increased vasoconstriction, or both. The fact that the FF approaches the same level in all age groups following pyrogen administration indicates that the differences are not entirely structural in nature and that the pyrogen has eliminated the inequalities of a physiologic mechanism which maintained the resting efferent arteriolar tonus at a higher level in the $\mathrm{O}$ than the $\mathrm{Y}$ group.

The calculations of renal resistances indicate an increase in both $R_{a}$ and $R_{e}$ in the resting state with age. During the response to pyrogen, both values diminish in subjects of all ages, so that at the height of the response the age differences are reduced but not entirely eliminated. The fall in $R_{a}$ is striking in the old group as compared to that in the young. The absolute and per cent decrement observed in $R_{e}$ indicates a greater degree of reversible resistance of the efferent renal arterioles in the old than in the young subjects. From the relationships between pressure and flow the presence of an initially increased $R_{e}$ and the ability of the efferent arterioles of the aged kidney to dilate may be inferred.

\section{SUMMARY}

1. The renal hemodynamic response to a standard dosage of pyrogen was measured in 54 sub- 
jects divided into three age groups : $20-49$ years, $50-69$ years, and $70-85$ years.

2. The baseline $\mathrm{C}_{\mathrm{IN}}$ declined progressively with advancing age. No significant change in $\mathrm{C}_{\mathrm{IN}}$ occurred during the course of the pyrogen reaction in any age group.

3. The mean baseline $C_{\mathbf{P A B}}$ declined progressively with advancing age. During the pyrogen reaction, the proportionate increase in $\mathrm{C}_{\mathrm{PAB}}$ for all age groups was approximately the same.

4. Although the baseline $\mathrm{FF}$ for the $\mathrm{O}$ group was significantly higher than the $\mathrm{Y}$ group, the minimum FF reached in all three groups was essentially the same.

5. The systolic blood pressure was lowest in the $\mathrm{Y}$ group, and did not change throughout the reaction. The systolic pressure fell significantly in the $\mathrm{M}$ and $\mathrm{O}$ groups during the reaction.

6 . The diastolic blood pressure started at the same level and fell to the same degree during the reaction in all groups.

7. The baseline $R_{a}$ was higher, and the fall in $R_{a}$ during the reaction was greater in the older age groups than in the young group.

8. The efferent resistance $\left(R_{e}\right)$ was significantly higher in each older group than in the $\mathrm{Y}$ group and in general paralleled the changes in FF following the administration of pyrogen. However, the minimum $R_{e}$ attained by the $O$ group remained significantly higher than the minimum $R_{e}$ attained by the $Y$ group.

\section{CONCLUSION}

It has been demonstrated that the administration of pyrogen is followed by a uniform percentage increase in renal blood flow in all age groups. Since filtration fraction fell to similar values in all age groups it is inferred that the renal arterioles are capable of dilating in the aged kidney. It is therefore concluded that the reduced renal blood flow observed in the aged is in part reversible and therefore not the result of structural changes in the renal vessels alone.

\section{ACKNOWLEDGMENTS}

We are indebted to Dr. John Bechtold for assistance in providing patients for this study; to Dr. R. W. Haines for making ophthalmological examination of the patients; and to Dr. Milton Landowne for suggestions in the analysis and interpretation of the results. Assistance in the chemical analyses was provided by Mrs. Elsie Beard, Miss Margaret McCollum, Mr. Charles Punte, Mr. Robert
Faid, Mrs. Eleanor Roach, Mr. Irving Jones, Mr. Arthur Dinan, Mr. Millard Starnes, and Mr. Gilbert Bellistri.

\section{REFERENCES}

1. Lewis, W. H., Jr., and Alving, A. S., Changes with age in the renal function in adult men; clearance of urea; amount of urea nitrogen in the blood; concentrating ability of the kidneys. Am. J. Physiol., 1938, 123, 500 .

2. Davies, D. F., and Shock, N. W., Age changes in glomerular filtration rate, effective renal plasma flow, and tubular excretory capacity in adult males. $\mathrm{J}$. Clin. Invest., 1950, 29, 496.

3. Miller, J. H., McDonald, R. K., and Shock, N. W., Age changes in the maximum tubular reabsorption of glucose. (To be published.)

4. Mortitz, A. R., and Oldt, M. R., Arteriolar sclerosis in hypertensive and non-hypertensive individuals. Am. J. Path., 1937, 13, 679.

5. Williams, R. H., and Harrison, T. R., A study of the renal arteries in relation to age and to hypertension. Am. Heart J., 1937, 14, 645.

6. Oliver, J. R., in Problems of Ageing, E. V. Cowdry, Editor. Williams \& Wilkins Co., Baltimore, 1942, 2nd Edition, p. 302.

7. Bell, E. T., Renal Disease. Lea \& Febiger, Philadelphia, 1946, p. 312.

8. Chasis, H., Ranges, H. A., Goldring, W., and Smith, H. W., The control of renal blood flow and glomerular filtration in normal man. J. Clin. Invest., 1938, 17, 683.

9. Goldring, W., and Chasis, H., Hypertension and $\mathrm{Hy}$ pertensive Disease. The Commonwealth Fund, New York, 1944, p. 195.

10. Harrison, H. E., A modification of the diphenylamine method for determination of inulin. Proc. Soc. Exper. Biol. \& Med., 1942, 49, 111.

11. Bratton, A. C., and Marshall, E. K., Jr., A new coupling component for sulfanilamide determination. J. Biol. Chem., 1939, 128, 537.

12. Smith, H. W., Finkelstein, N., Aliminosa, L., Crawford, B., and Graber, M., The renal clearances of substituted hippuric acid derivatives and other aromatic acids in dog and man. J. Clin. Invest., 1945, 24, 388.

13. Van Slyke, D. D., Determination of urea by gasometric measurement of the carbon dioxide formed by the action of urease. J. Biol. Chem., 1927, 73, 695.

14. Peters, J. P., and Van Slyke, D. D., Quantitative Clinical Chemistry. Volume II, Methods. Williams \& Wilkins Co., Baltimore, 1932, p. 691.

15. Lamport, $H$., Improvements in calculation of renal resistance to blood flow. Charts for osmotic pressure and viscosity of blood. J. Clin. Invest., 1943, 22, 461.

16. Moore, R. A., The total number of glomeruli in the normal human kidney. Anat. Rec., 1931, 48, 153.

17. Miller, J. H., McDonald, R. K., and Shock, N. W., Renal extraction of para-aminohippurate in the aged individual. J. Gerontol., in press. 